\title{
Yersinia Enterocolitis May Mimic Appendicitis: 12 Years of Experience in a Single Tertiary Center
}

\author{
Sara Fernandes ${ }^{a}$ Sofia Vasconcelos-Castro ${ }^{a}$ Cláudia Teixeira $^{b-d}$ \\ Miguel Soares-Oliveira ${ }^{a, c}$ \\ a Department of Pediatric Surgery, Centro Hospitalar Universitário São João, Porto, Portugal; ${ }^{b}$ Department of \\ Clinical Pathology, Centro Hospitalar Universitário São João, Porto, Portugal; ' ${ }^{\top}$ Faculty of Medicine, University of \\ Porto, Porto, Portugal; ${ }^{d}$ UCIBIO/REQUIMTE, University of Porto, Porto, Portugal
}

\section{Keywords}

Appendicitis · Pseudo-appendicitis · Yersinosis ·

Enterocolitis

\section{Abstract}

Introduction: Yersinia enterocolitica infection is a zoonotic disease that varies from self-limited gastroenteritis to more severe forms. Its propensity to affect the terminal ileum and to spread to regional lymph nodes explains the potential misdiagnosis with appendicitis. Methods: We reviewed the $Y$. enterocolitica infection cases in a pediatric population for the last 12 years. Results: There were 11 cases of $Y$. enterocolitica infection in the selected period. Four patients had a suspected surgical diagnosis: 1 intussusception, 3 acute appendicitis. Patients who presented with appendicitis-like features were older, whereas younger children most commonly presented with diarrhea and fever. Ultrasound and abdominal computed tomography (CT) were performed in appendicitis-like patients and ruled out appendicitis in 2 of the 3 cases. The only patient submitted to surgery had abnormal CT findings and an important risk factor for this infection that was not recognized at presentation. Conclusion: This condition should be considered in patients with known

karger@karger.com www.karger.com/pjg

Karger

BOPEN ACCESS
(C) 2020 Sociedade Portuguesa de Gastrenterologia Published by S. Karger AG, Basel

This article is licensed under the Creative Commons AttributionNonCommercial-NoDerivatives 4.0 International License (CC BYNC-ND) (http://www.karger.com/Services/OpenAccessLicense). Usage and distribution for commercial purposes as well as any distribution of modified material requires written permission. risk factors (such as iron overload) and with the right epidemiological setting when presenting with abdominal symptoms. The suspicion of this diagnosis in these particular cases might obviate unnecessary surgical interventions.

(c) 2020 Sociedade Portuguesa de Gastrenterologia Published by S. Karger AG, Basel

\section{Enterocolite por Yersinia mimetizando apendicite} aguda: 12 anos de experiência de um centro terciário

Palavras Chave

Apendicite $\cdot$ Pseudo-apendicite $\cdot$ Yersinose $\cdot$ Enterocolite

\section{Resumo}

Introdução: A infecção por Yersinia enterocolitica é uma zoonose que se pode apresentar como uma gastroenterite auto-limitada ou assumir formas mais graves. A sua propensão em afectar o íleo terminal e, consequentemente, os gânglios linfáticos regionais explica o potencial confundimento diagnóstico com a apendicite aguda. Métodos: Foram revistos todos os casos reportados de infecção por $Y$. enterocolitica em população pediátrica, 
nos últimos 12 anos. Resultados: Foram identificados 11 casos de infecção por Y. enterocolitica no período selecionado. Em 4 destes pacientes foi suspeitado inicialmente um diagnóstico cirúrgico: 1 invaginação intestinal e 3 apendicites agudas. Os doentes que apresentaram caraterísticas típicas de apendicite aguda eram mais velhos, enquanto os pacientes de menor idade mais comumente se apresentaram com diarreia e febre. Nos doentes com suspeita de apendicite, a ecografia e a tomografia computorizada abdominal foram realizadas em todos os doentes e excluíram o diagnóstico em $2 / 3$ casos. $O$ único paciente submetido a cirurgia tinha relato de alterações radiológicas típicas de apendicite aguda e apresentava um factor de risco importante para a infecção por Y. enterocolitica que não foi inicialmente reconhecido. Conclusão: O diagnóstico de Yersinose deve ser suspeitado em doentes com sintomas gastrointestinais que apresentem fatores de risco (sobrecarga de ferro) e o contexto epidemiológico adequado. A suspeição precoce deste diagnóstico neste contexto pode evitar intervenções cirúrgicas desnecessárias.

(c) 2020 Sociedade Portuguesa de Gastrenterologia Publicado por S. Karger AG, Basel

\section{Introduction}

Yersinia enterocolitica is a siderophilic gram-negative bacillus of the Enterobacteriaceae family, with a predisposition to affect the terminal ileum and cecum and the possibility to cause mesenteric lymphadenitis $[1,2]$. Its clinical picture may resemble that of appendicitis, infrequently leading to potentially unnecessary surgical interventions $[2,3]$.

We present a series of $Y$. enterocolitica abdominal infection during a 12-year period with particular attention to its possible misdiagnosis with appendicitis, mainly in older children, even after imagiological investigation.

\section{Materials and Methods}

We have designed a retrospective study by reviewing the medical records of all patients with Y. enterocolitica infection evaluated at a tertiary center between November 2007 and July 2019. Patients were selected by a positive result on a biologic specimen culture (stool and peritoneal fluid) after observation at the emergency department or after admission as inpatients.

Only patients between 0 and 18 years by the time of infection were included. Data on age, gender, clinical presentation, duration of symptoms, imagiological studies, laboratory results, surgical consultation and treatment were collected. Patients with abdomi- nal pain at presentation were further analyzed and compared with the others.

Stool samples were plated on Mac Conkey agar (MCK; bioMérieux) and Yersinia CIN agar (YER; bioMérieux) and also inoculated into selenite enrichment broth (BD BBL Selenite-F Broth; Becton Dickinson), which was subcultured after $48 \mathrm{~h}$ of incubation. MCK agar plates were incubated at $37^{\circ} \mathrm{C}$ and examined after 24 and $48 \mathrm{~h}$; suspected isolates were identified and serotyped if appropriate. YER agar plates were incubated at both 25 and $37^{\circ} \mathrm{C}$ and examined after 24, 48, and $72 \mathrm{~h}$; colonies presenting typical "bullseye" morphology were selected for further testing. Peritoneal fluid samples were plated on Columbia Agar with 5\% Sheep Blood (COS; bioMérieux) and Mac Conkey agar (MCK; bioMérieux), and also inoculated into thioglycollate enrichment broth (Thioglycollate Medium USP; VWR Chemicals), which was subcultured into COS agar. Agar plates were incubated at $37^{\circ} \mathrm{C}$ and examined after 24 and $48 \mathrm{~h}$. Suspected isolates were identified by the VITEK MS system (bioMérieux). Antimicrobial susceptibility profiles of the isolates were determined by the VITEK 2 system (bioMérieux).

A descriptive analysis of the data was performed by using Microsoft Excel.

\section{Results}

There were 11 confirmed cases of $Y$. enterocolitica infection during the studied period. Patients' demographics and management are shown in Table 1 . Seven patients were male (63.6\%), and the median age was 1 year (range $0.5-14)$. Patient 11 was the only one with a positive past medical history: she suffered from hemochromatosis secondary to transfusion dependent-beta thalassemia.

The most frequent features at presentation were diarrhea $(n=8)$ and fever $(n=8)$, which were present in $72.7 \%$ of the patients. Four patients $(4 / 11,36.4 \%)$ presented with abdominal pain (Patients 3, 8, 10, and 11 - Group A). As depicted in Table 1, all patients who presented with abdominal pain in the abdominal right lower quadrant (RLQ) resembling acute appendicitis were older than 9 years (Patients 8, 10, and 11 - Group A1). Only in these 3 patients, an abnormal abdominal examination at presentation was reported, mostly tenderness in the abdominal RLQ, and 1 patient showed an abdominal RLQ palpable mass (patient 11). The remaining patients were younger and presented more commonly with diarrhea and fever (Group B). There is only 1 exceptional case of a 12-yearold boy (Patient 9) who presented with the most typical feature for Y. enterocolitica infection and not with abdominal pain. A comparison of clinical presentation, evaluation, and treatment between Groups A and B is shown in Table 2. The median time for duration of symptoms at presentation was 2 days (range 1-12). Analytic findings 


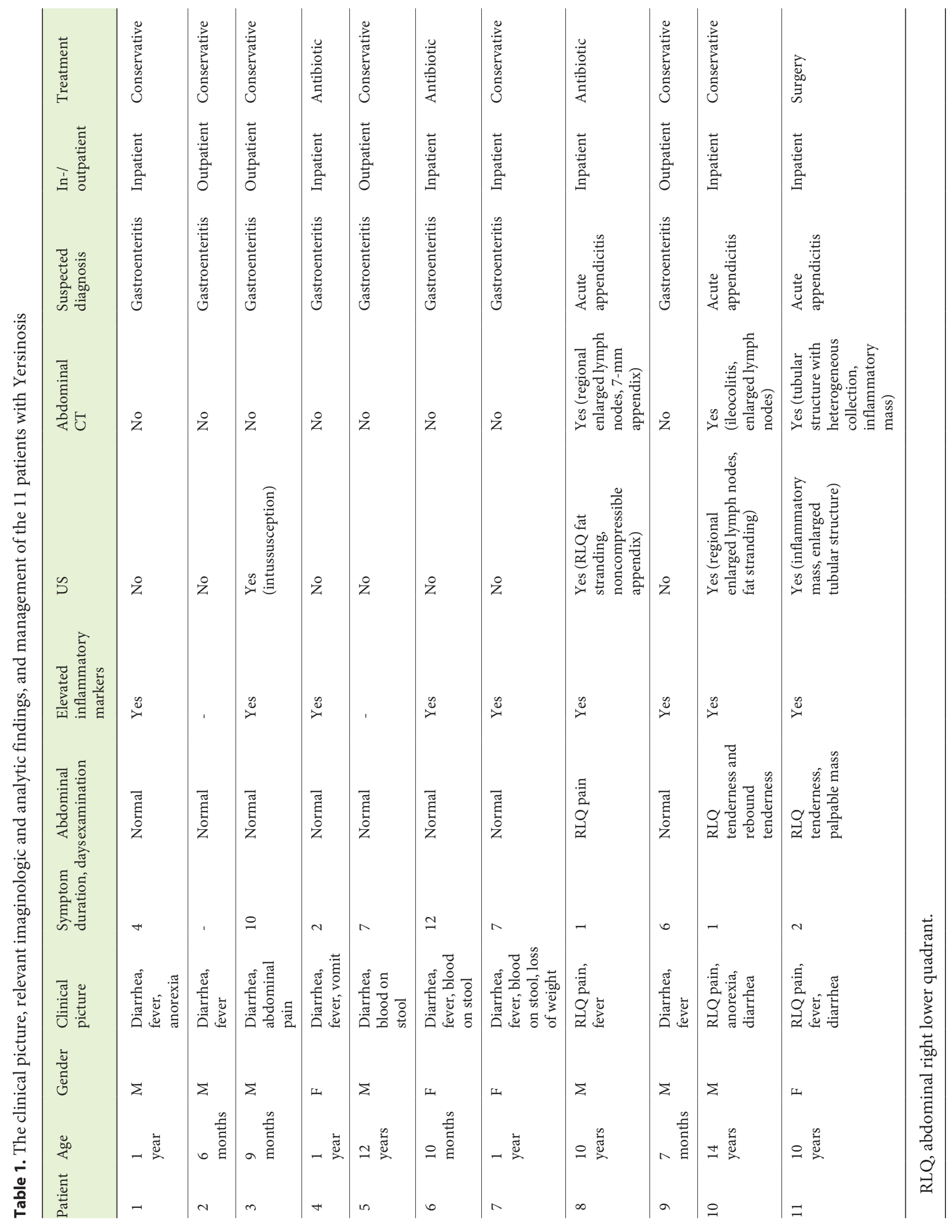


Table 2. Data summary per patient group

\begin{tabular}{llll}
\hline & $\begin{array}{l}\text { Group A } \\
\text { (abdominal pain, } n=4)\end{array}$ & $\begin{array}{l}\text { Group B (no } \\
\text { abdominal pain, } \\
n=7)\end{array}$ \\
\cline { 2 - 4 } & A1 & A2 & $1,2,4,5,6,7,9$ \\
\hline Patient number & $8,10,11$ & 3 & 0 \\
Positive medical history & $1 / 3(33 \%)$ & 0 & No \\
Abdominal tenderness & Yes & No & None \\
Radiological evaluation & US, CT & US & GE \\
Suspected diagnosis & AA & SBI & No \\
Surgical evaluation & Yes & Yes & 0 \\
Surgical intervention & $1 / 3(33 \%)$ & 0 & 0 \\
\hline
\end{tabular}

AA, acute appendicitis; CT, computed tomography; GE, gastroenteritis; SBI, small bowel intussusception; US, ultrasound.

were positive for elevation of inflammatory markers in 9 (81.8\%) patients and in all cases of Group A1.

Ultrasound (US) was performed in all patients from Group A: 1 case showed an ileo-ileal intussusception, 2 patients had inflammatory signs on the abdominal RLQ, and an inflammatory mass involving the small intestine and the appendix was present in Patient 11. These patients were evaluated by a pediatric surgeon and, excluding Patient 3 whose intussusception resolved spontaneously, all others (Group A1) underwent an abdominal computed tomography (CT) scan under the suspicion of acute appendicitis. In Patient 11, CT showed features compatible with complicated acute appendicitis associated with an inflammatory mass, and a conservative approach with antibiotics and surveillance was decided. Five days later, this patient showed no clinical improvement, and repeated US revealed multiple peritoneal abscesses and secondary hydronephrosis. Laparotomy was performed: an inflammatory mass was identified, involving ileal segments, the appendix and the cecum, and there was no macroscopic contamination of the peritoneal cavity. The appendix showed mild inflammatory signs, and ileal perforation was discovered, creating doubt about whether it happened during the manipulation of the inflammatory mass or whether it had already been there before, representing a form of invasive enteritis. An appendectomy, a segmental ileal resection, and primary anastomosis were performed. Histologic analysis demonstrated signs of periappendicitis and inflammatory changes of the ileal segment resected, concordant with the macroscopic changes seen intraoperatively, without disclosure of the nature of the perforation. The postoperative course was uneventful, and the patient was discharged on the 8th postoperative day.

Yersinia Enterocolitis Mimicking Appendicitis
The majority of patients (63.6\%) were treated as inpatients. The cases of suspected appendicitis (Group A1) were managed differently after admission: 1 with conservative treatment (fluids and analgesics), 1 with intravenous antibiotics, and 1 with surgical treatment. Four cases of suspected gastroenteritis were managed conservatively and on an outpatient basis. All patients showed unremarkable evolution after treatment.

\section{Discussion and Conclusion}

Y. enterocolitica infection is an enteric illness often related to consumption of contaminated food or water and is a common cause of gastroenteritis in developing nations, but less common in the developed world $[1,4]$. The ingestion of contaminated material and the direct contact with the intestinal mucosa is the standard route of infection.

Clinical presentation is variable, and in immunocompetent patients it is typically a self-limited enteritis/colitis with secretory diarrhea, fever, abdominal pain, and rarely emesis [4]. Diarrhea is the most common clinical feature in children $<5$ years of age $[1,2]$. Older children and adolescents (5-14 years of age) often present with abdominal pain in the abdominal RLQ because of terminal ileitis and mesenteric lymphadenitis, the so called pseudoappendicitis $[1,2]$. This might be explained by the preferential involvement of the terminal ileum and cecum.

US and CT remain the mainstay of diagnostic approach to discriminate appendicitis from appendicitis-like syndrome caused by Y. enterocolitica, as stool cultures and serological studies are considered only as supplementary investigations in the diagnosis because of the long time

GE Port J Gastroenterol 2021;28:26-31 DOI: $10.1159 / 000507555$ 
until the definitive results $[3,5]$. In this series, all 3 cases with abdominal RLQ pain and suspected appendicitis (Group A1) were $>9$ years old. Patient 11 showed an abdominal RLQ palpable and tender mass on examination, a feature often seen in appendicitis but rarely described in the literature as a feature of Yersinosis [5]. Patients with abdominal pain had abnormal US findings that warranted further investigation with CT scans in most of them. In all but 1 patient, CT could exclude appendicitis. In 1 case (Patient 11), US and abdominal CT showed typical findings of appendicitis, and the patient ultimately underwent surgery. There are reports of CT findings changing quickly over time, supporting the importance of serial clinical observation of these patients [6].

However, there are a few clues in the clinical presentation and epidemiological settings that may help suspecting $Y$. enterocolitica infection. Patients may present with extraintestinal complications such as reactive arthritis, erythema nodosum, and conjunctivitis $[1,5]$. The history of ingestion of potentially originally contaminated food products (undercooked pork, unpasteurized milk) or secondarily contaminated food (vegetables) or water by the excrements of household animals are important epidemiological factors that might be investigated [2]. Iron overload is an important risk factor for infection and for disseminated forms of the disease [7]. Furthermore, in children using chelating agents, the virulence of Y. enterocolitica is enhanced because it provides iron as a siderophore for their growth [7, 8]. Reed et al. [9] found that $50 \%$ of the patients from a review of 12 patients with $Y$. enterocolitica peritonitis had iron overload. Only 1 patient of our series had a known risk factor for Y. enterocolitica infection: Patient 11 had beta thalassemia major and a secondary hemochromatosis on chelating agents, which was not recognized at admission, and she ultimately underwent surgery. Therefore, a careful clinical history and examination, allied to accurate imaging, are of paramount importance for a correct diagnosis, thus avoiding unnecessary invasive treatments such as surgery. In fact, most $Y$. enterocolitis infections are self-limited, and treatment with antibiotics is recommended only for severe or complicated diarrhea infections [10, 11].

Although most of the reports highlight the importance of early recognition of this infection to avoid unnecessary surgery, there are some reports of surgical treatment for complicated $Y$. enterocolitica infections, such as intractable abdominal pain, intussusception, intestinal obstruction, perforation, and peritonitis $[3,5]$. Greco et al. [8] reported the need of surgery in 3 of the 4 cases of Yersinosis in patients with iron overload. Kimura and Sasaki
[12] also reported a case in which surgery was required for intractable Yersinosis. In our series, besides the patient with beta thalassemia who underwent surgery, there was also 1 case of intussusception secondary to $Y$. enterocolitica enteritis, but the patient did not require surgical intervention.

As stressed by our case series, Yersinosis is rare but can mimic appendicitis and should be considered in older children as a cause of abdominal RLQ pain. Investigation of possible iron overload, ingestion of contaminated food products, and extraintestinal presentations may be of paramount importance to the diagnosis and to avoid unnecessary surgery, as even CT may induce misdiagnosis. Treatment is mainly conservative, with surgical intervention being reserved only for complicated cases.

\section{Statement of Ethics}

The study protocol was approved by the institute's committee on human research.

Despite the involvement of humans in the study, the authors were not able to obtain informed consent from all individual participants because of the study's retrospective and observational nature.

\section{Disclosure Statement}

The authors have no conflicts of interest to declare.

Funding Sources

The authors have no funding sources to declare.

\section{Author Contributions}

All authors contributed to the study conception and design. Material preparation, data collection and analysis were performed by Sara Fernandes, Sofia Vasconcelos-Castro, and Claudia Teixeira. The first draft of the manuscript was written by Sara Fernandes, and all authors commented on previous versions of the manuscript. All authors read and approved the final version of the manuscript.

References

1 Rosner BM, Werber D, Höhle M, Stark K Clinical aspects and self-reported symptoms of sequelae of Yersinia enterocolitica infections in a population-based study, Germany 2009-2010. BMC Infect Dis. 2013 May;13(1): 236
30

GE Port J Gastroenterol 2021;28:26-31 DOI: $10.1159 / 000507555$
Fernandes/Vasconcelos-Castro/Teixeira/ Soares-Oliveira 
2 Zińczuk J, Wojskowicz P, Kiśluk J, Fil D, Kemona A, Dadan J. Mesenteric lymphadenitis caused by Yersinia enterocolitica. Prz Gastroenterol. 2015;10(2):118-21.

3 Perdikogianni C, Galanakis E, Michalakis M, Giannoussi E, Maraki S, Tselentis Y, et al. Yersinia enterocolitica infection mimicking surgical conditions. Pediatr Surg Int. 2006 Jul; 22(7):589-92

4 Hsu G, Jones A, Thornton B. Invasive Yersiniosis in a Pediatric Patient With $\beta$-Thalassemia Major: Acute Decompensation After Rapid Blood Transfusion. Pediatr Emerg Care. 2019 Jul;35(7):e118-20.

5 Sakellaris G, Kakavelakis K, Stathopoulos E, Michailidou H, Charissis G. A palpable right lower abdominal mass due to Yersinia mesenteric lymphadenitis. Pediatr Surg Int. 2004 Feb;20(2):155-7.
6 Antonopoulos P, Constantinidis F, Charalampopoulos G, Dalamarinis K, Karanicas I, Kokkini G. An emergency diagnostic dilemma: a case of Yersinia enterocolitica colitis mimicking acute appendicitis in a $\beta$-thalassemia major patient: the role of $\mathrm{CT}$ and literature review. Emerg Radiol. 2008 Mar; 15(2):123-6.

7 Al-Salem AH, Elbashier AM, Al Nazer M. Yersinia enterocolitica colitis with peritonitis in a child with beta-thalassemia major. Ann Saudi Med. 2002 Sep-Nov;22(5-6):339-40.

8 Greco L, Marino F, Gentile A, Catalano G, Angilletta D. Yersinia enterocolitica ileocolitis in beta-thalassemic patients. Colorectal Dis. 2006 Jul;8(6):525-30.

9 Reed RP, Robins-Browne RM, Williams ML. Yersinia enterocolitica peritonitis. Clin Infect Dis. 1997 Dec;25(6):1468-9.
10 Cover TL, Aber RC. Yersinia enterocolitica. N Engl J Med. 1989 Jul;321(1):16-24.

11 Guarino A, Albano F, Ashkenazi S, Gendrel D, Hoekstra JH, Shamir R, et al.; European Society for Paediatric Gastroenterology, Hepatology, and Nutrition; European Society for Paediatric Infectious Diseases. European Society for Paediatric Gastroenterology, Hepatology, and Nutrition/European Society for Paediatric Infectious Diseases evidence-based guidelines for the management of acute gastroenteritis in children in Europe. J Pediatr Gastroenterol Nutr. 2008 May;46(2 Suppl 2):S81-122.

12 Kimura J, Sasaki K. Yersinia pseudotuberculosis infection intractable by antibiotics: A rare case report. Int J Surg Case Rep. 2016;21: $139-41$. 